\title{
Teste de condutividade elétrica para determinação do potencial fisiológico de sementes de aveia branca
}

\section{The electrical conductivity test to assess physiological quality of white oat seeds}

\author{
Julhana Cristina Sponchiado'; Clovis Arruda Souza²; \\ Cileide Maria Medeiros Coelho ${ }^{3}$
}

\begin{abstract}
Resumo
A determinação da condutividade elétrica $(\mathrm{CE})$ constitui um teste rápido e de fácil execução para avaliação do vigor de sementes. No entanto, ainda faltam informações sobre a eficiência e tempo de embebição para o teste CE na avaliação do vigor das sementes de aveia branca. Assim, o presente trabalho teve como objetivo avaliar os efeitos do período de embebição na condutividade elétrica e verificar a eficiência comparativa com outros testes de vigor em sementes dessa espécie. O experimento foi conduzido utilizando-se oito lotes de sementes de aveia branca da cultivar URS Guria, sendo quatro provenientes de plantas tratadas com fungicida e quatro sem aplicação de fungicida durante o ciclo da cultura. $\mathrm{O}$ teste de $\mathrm{CE}$ foi conduzido à temperatura de $20^{\circ} \mathrm{C}$, por períodos de $2,4,8,12,16,24,36 \mathrm{e}$ 48 horas de imersão, em $50 \mathrm{~mL}$ de água destilada, utilizando-se $2 \mathrm{~g}$ de sementes. Realizou-se também teste de germinação, primeira contagem, emergência em areia, índice de velocidade de emergência, comprimento de plântula, leitura de potássio e envelhecimento acelerado. Foi adotado delineamento inteiramente casualizado, com quatro repetições. Com tempo de embebição de duas horas já é possível distinguir lotes quanto à qualidade fisiológica das sementes estudadas, com base no teste CE. Os lotes de sementes provenientes de plantas tratadas com fungicida possuem maior vigor. $\mathrm{O}$ teste de condutividade elétrica se correlacionou negativamente e significativamente $(\mathrm{P}<0,05)$ com os testes de vigor: primeira contagem da germinação, emergência em areia e índice de velocidade de emergência e também correlação negativa, porém fraca $(\mathrm{P}<0,10)$ com os testes de: germinação, envelhecimento acelerado, comprimento de plântula e lixiviação de potássio. O teste de condutividade elétrica é eficiente, sendo indicado para avaliar o potencial fisiológico de sementes de aveia branca.
\end{abstract}

Palavras-chave: Avena sativa, efluxo de eletrólitos, vigor de sementes

\begin{abstract}
The measurement of electrical conductivity (EC) is a quick and easy test to evaluate seed vigor. However, for seeds of white oat still lacking such information on effectiveness and time of imbibition for EC test. Thus, the present study aimed to evaluate the effects of soaking time on the values of electrical conductivity and verify the efficiency in comparison with other vigor tests applied on white oat seeds. The experiment was conducted using eight seed lots white oat cultivar URS Guria, spliced into four lots from plants treated with fungicide and four lots from without fungicide application on plant shoot during the crop cycle. The EC test was conducted at $20{ }^{\circ} \mathrm{C}$ for $2,4,8,12,16,24,36$ and
\end{abstract}

\footnotetext{
${ }^{1}$ Discente do Curso de Doutorado do Programa de Pós-Graduação em Produção Vegetal, Universidade do Estado de Santa Catarina, UDESC, Lages, SC. E-mail: julhanasponchiado@gmail.com

${ }^{2}$ Prof. Associado do Dept ${ }^{\circ}$ de Agronomia, Centro de Ciências Agroveterinárias, UDESC, Lages, SC. E-mail: clovis.souza@udesc.br

${ }^{3}$ Prof $^{\mathrm{a}}$ Adjunta do Dept ${ }^{\mathrm{o}}$ de Agronomia, Centro de Ciências Agroveterinárias, UDESC, Lages, SC. E-mail: cileide.coelho@pq.cnpq.br

* Autor para correspondência
} 
48 hours immersion of $2 \mathrm{~g}$ seeds in $50 \mathrm{~mL}$ of distilled water. Were also conducted test's germination, first count of germination, sand emergence, speed of emergence index, seedling length, potassium leakage and accelerated aging. Were adopted a completely randomized design with four replications. The results pointed to seed imbibed for two hours are sufficient to possibilities to splice lots differing on its physiological quality of seed for white oat, cv. URS Guria, based on the EC test. The seed lots from plants treated with fungicide showed highest physiological quality than seeds from plants not treated with fungicide. The electrical conductivity test correlated significantly $(\mathrm{P}<0.05)$, but negatively with vigor tests: first count of germination, sand emergence and speed of emergence index and also a negative correlation, but weak $(\mathrm{P}<0.10)$ with tests: germination, accelerated aging, seedling length and potassium efflux. It is found that the electrical conductivity is an efficient and suitable test for evaluating the physiological quality of white oat seeds.

Key words: Avena sativa, electrolytes efflux, vigor

\section{Introdução}

A aveia branca (Avena sativa L.) tem sido considerada como cultura alternativa na estação fria de grande importância em áreas de cultivo no Brasil. A demanda de aveia branca tem crescido nos últimos 10 anos, desempenhando um importante papel no sistema de produção, principalmente da região Sul do país (FONTANELI, 2012). Devido ao destaque que a cultura tem recebido, tanto na utilização de grãos para a indústria de alimentos humanos quanto para alimentação de animais ou para cobertura morta em sistemas de plantio direto, ressalta-se um maior cuidado com a qualidade das sementes utilizadas, buscando maiores produtividades e qualidade de sementes, bem como dos grãos produzidos.

A qualidade das sementes é um dos principais fatores que afetam o desempenho da cultura e está relacionada com os atributos genéticos, físicos, fisiológicos e sanitários que influenciam na capacidade destas em originar plantas de alta produtividade (MARCOS FILHO, 2005). Destes atributos, a avaliação do potencial fisiológico é fundamental em programas de controle de qualidade na produção de sementes, pois possibilita a identificação de lotes com distintos níveis de desempenho em diferentes condições ambientais. É uma característica avaliada através da germinação e vigor das sementes.

O vigor não é uma característica facilmente mensurável, mas proveniente de um conceito complexo, de ampla abordagem, sempre associado a um ou vários aspectos do desempenho da semente (TEKRONY, 2003). Portanto, ressalta-se a importância de testes que avaliem corretamente esta característica, especialmente para aveia branca, onde a pesquisa ainda não indica procedimentos padronizados para avaliação do vigor de sementes (BORSATO et al., 2000) que possam ser utilizados pelas empresas produtoras nas análises internas de controle de qualidade das sementes, para caracterizar as sementes destinadas à comercialização e também, nos laudos dos laboratórios oficiais de análise de sementes.

$\mathrm{O}$ teste de condutividade elétrica tem sido reconhecido como eficiente para a avaliação do vigor de sementes em várias espécies, onde a qualidade das sementes é avaliada indiretamente através da determinação da quantidade de lixiviados na solução de embebição das sementes. Os menores valores, correspondentes à menor liberação de exsudatos, indicam maior vigor pela menor intensidade de desorganização dos sistemas de membranas das células (VIEIRA; KRZYZANOWSKI, 1999). Trata-se de um teste rápido e eficiente (ANDRADE et al., 1995). No entanto, alguns fatores podem afetar os resultados do teste de condutividade elétrica. O tempo de embebição das sementes, onde a metodologia convencional recomenda um período de $24 \mathrm{~h}$, para ervilha (Pisum sativum L.), soja (Glycine max L. Merril), feijão (Phaseolus vulgaris L.) e milho (Zea mays L.) (BRUGGINK et al., 1991;HAMPTON; TEKRONY, 1995; VIEIRA; KRZYZANOWSKI, 1999; COELHO et al., 2010). 
Porém, mais recentemente vários trabalhos indiquem a possibilidade de utilização de períodos mais curtos. Já está demonstrada a distinção de lotes de sementes através do teste de condutividade elétrica em sementes de mamoneira (Ricinus communis L.) cv. AL Guarany 2002 em um período de quatro horas de embebição (SILVA; MARTINS, 2009), para café (Coffea arabica L.) em três horas e meia (PRETE; ABRAHÃO, 1995), para pinhão-manso (Jatropha curcas L.) em seis horas (ARAÚJO et al., 2011), para berinjela (Solanum melongena L.) cv. Preta Comprida, em quatro horas (ALVES et al., 2012), para milheto (Pennisetum americanum L.) cv. Comum e BN2 em duas horas (GASPAR; NAKAGAWA, 2002), rúcula (Eruca sativa L.), cv. Cultivada e Folha Larga com quatro horas (LEAL et al., 2012) e aveia preta (Avena strigosa Schcreb) em oito horas (MENEZES et al., 2007).

Assim, a pesquisa objetivou avaliar os efeitos do período de embebição nos valores de condutividade elétrica e verificar a eficiência comparativa com outros testes de vigor em sementes de aveia branca.

\section{Material e Métodos}

As sementes foram produzidas em experimento conduzido em condições de campo, no município de Lages-SC, em cambissolo alumínico com $\mathrm{pH}$ 6,3 na safra 2010. Segundo o Altas Climático da Região Sul do Brasil (RADIN; REISSER JÚNIOR; PANDOLFO, 2011), o município Lages está localizado no Planalto Sul de Santa Catarina, com altitude média de $930 \mathrm{~m}$, latitude sul de $27^{\circ} 48^{\prime} 58^{\prime \prime}$ e longitude oeste de 50 $19^{\prime} 34^{\prime \prime}$, temperatura média de $15^{\circ} \mathrm{C}$ com precipitação anual de $1.500 \mathrm{~mm}$.

A cultivar utilizada foi a URS Guria. A semeadura foi realizada em 30 de julho de 2010, em sistema de semeadura direta (sendo o cultivo anterior feijão), na densidade de 350 sementes aptas. $\mathrm{m}^{-2}$. Cada parcela foi constituída de cinco linhas de cinco metros de comprimento, espaçadas 0,2 metro entrelinhas, e a 0,5 metro entre parcelas. Foram colhidas apenas as 3 linha centrais. A adubação de base foi realizada com $398 \mathrm{~kg} \cdot \mathrm{ha}^{-1}$ da fórmula 07-28-14 (N- $\left.\mathrm{P}_{2} \mathrm{O}_{5}-\mathrm{K}_{2} \mathrm{O}\right)$ e uma adubação de cobertura com nitrogênio (ureia) de $34 \mathrm{~kg} \cdot \mathrm{ha}^{-1}$ de $\mathrm{N}$ no estádio de perfilhamento. $\mathrm{Na}$ detecção das primeiras pústulas de ferrugem, as parcelas experimentais foram divididas, sendo que metade delas recebeu aplicação do fungicida tebuconazole (150 g.ha-1 do i.a), posteriormente (intervalos de 15 e 30 dias), aplicou-se a mistura comercial de tebuconazole (113 g.ha-1 do i.a) e trifloxistrobina (56 g.ha-1 do i.a). E a outra metade não recebeu aplicação de fungicida. O delineamento foi em blocos ao acaso, com três repetições.

Para a realização do experimento em laboratório, as sementes foram subdivididas em oito lotes, sendo quatro provenientes de plantas pulverizadas com fungicida (CF) e quatro sem tratamento com fungicida (SF) na parte aérea da planta de aveia branca. Cada amostra (lote) foi colocada em estufa por $24 \mathrm{~h}$ em diferentes temperaturas $(25,30,40$ e $50{ }^{\circ} \mathrm{C}$ ), assim obtendo oito diferentes lotes de sementes: $1\left(1 \mathrm{CF} 25^{\circ} \mathrm{C}\right), 2\left(1 \mathrm{SF} 25^{\circ} \mathrm{C}\right), 3(2 \mathrm{CF}$ $\left.30^{\circ} \mathrm{C}\right), 4\left(2 \mathrm{SF} 30^{\circ} \mathrm{C}\right), 5\left(3 \mathrm{CF} 40^{\circ} \mathrm{C}\right), 6\left(3 \mathrm{SF} 40^{\circ} \mathrm{C}\right)$, $7\left(4 \mathrm{CF} 50^{\circ} \mathrm{C}\right), 8\left(4 \mathrm{SF} 50^{\circ} \mathrm{C}\right)$. Estes procedimentos visaram gerar modificações menores nos níveis de vigor das sementes.

Os testes de vigor foram conduzidos no laboratório de sementes da Universidade do Estado de Santa Catarina-UDESC, Campus de Lages. As sementes foram submetidas aos seguintes testes:

Teor de água das sementes - Realizado pelo método da estufa a $105 \pm 3^{\circ} \mathrm{C}$, durante $24 \mathrm{~h}$, de acordo com as Regras para Análise de Sementes (BRASIL, 2009).

Teste de germinação (G) - Realizou-se com quatro repetições de 100 sementes, semeadas em papel Germitest umedecido com água destilada, na proporção de 2,5 vezes o peso do papel seco. Conduzido em câmara tipo BOD (Oxylab, Modelo Oxy 108), mantida à temperatura de $20 \pm 1{ }^{\circ} \mathrm{C}$ e com umidade relativa do ar maior que $90 \%$, as contagens foram realizadas no décimo dia após a semeadura, seguindo as Regras para Análise de 
Sementes (BRASIL, 2009).

Primeira contagem da germinação (PCG) Conduzido juntamente com o teste de germinação, determinou-se a percentagem de plântulas normais no quinto dia após a instalação do $\mathrm{G}$, os resultados foram expressos em percentagem de plântulas normais (BRASIL, 2009).

Emergência em areia (AREIA) - Utilizouse quatro repetições de 100 sementes de cada tratamento, semeou-se em canteiro contendo areia. O teste foi realizado em condições de campo, nos meses de abril e maio de 2012. Durante a condução do teste, foram realizadas irrigações quando necessárias para manter o substrato com umidade adequada e os canteiros foram mantidos cobertos com sombrite para $25 \%$ de atenuação da radiação solar. A contagem ocorreu no $10^{\circ}$ dia após a semeadura (BRASIL, 2009).

Índice de velocidade de emergência (IVE) Este teste foi realizado juntamente com o teste de emergência em areia (AREIA), foram avaliados diariamente o número de plântulas emergidas do $4^{\circ}$ ao $15^{\circ}$ dia após a semeadura. O índice foi calculado conforme a fórmula proposta por Maguire (1962): $\mathrm{IVG}=\mathrm{G} 1 / \mathrm{N} 1+\mathrm{G} 2 / \mathrm{N} 2+\ldots+\mathrm{Gn} / \mathrm{Nn}$ onde: $\mathrm{G} 1, \mathrm{G} 2$, $\mathrm{Gn}=$ número de plântulas germinadas na primeira, segunda, até a última contagem e N1, N2, Nn = número de dias desde a primeira, segunda, até a última contagem.

Comprimento de plântula (CP) - Avaliouse o comprimento médio de 10 plântulas normais, escolhidas aleatoriamente, obtidas a partir da semeadura de quatro repetições de 20 sementes, em papel Germitest. Os rolos de papel contendo as sementes permaneceram por cinco dias em germinador, à temperatura de $20^{\circ} \mathrm{C}$. A avaliação do comprimento das plântulas foi feita com auxílio de uma régua milimetrada.

Envelhecimento acelerado (EA) - Utilizaramse 240 sementes sobre tela e $40 \mathrm{~mL}$ de água em cada caixa transparente com tampa $(11 \times 11 \times 3,5 \mathrm{~cm})$, posteriormente, levados à $\mathrm{BOD}$ regulada à $41^{\circ} \mathrm{C}$, onde permaneceram por $48 \mathrm{~h}$, seguindo adequação do teste realizado por Tunes et al. (2008). Após período de envelhecimento, foi determinado o teor de água das sementes, pelo método da estufa a $105 \pm$ $3{ }^{\circ} \mathrm{C}$, por $24 \mathrm{~h}$ (BRASIL, 2009), onde foram usadas duas repetições de 20 sementes. Com as 200 sementes restantes, foi realizado o teste de germinação padrão, onde utilizou-se quatro repetições de 50 sementes, semeadas em papel Germitest umedecido com água destilada, na proporção de 2,5 vezes o peso do papel seco. Conduzido em câmara tipo BOD e mantidos à temperatura de $20{ }^{\circ} \mathrm{C}$, a contagem de plântulas normais foi realizada no quinto dia após a semeadura do G.

\section{Condutividade elétrica (CE) - Utilizou-se} quatro amostras com $2 \mathrm{~g}$ de sementes para cada tratamento. As amostras foram pesadas em balança de precisão e, a seguir, colocadas para embebição em copos plásticos contendo $50 \mathrm{~mL}$ de água destilada. As sementes foram mantidas em câmara tipo BOD, à temperatura de $20{ }^{\circ} \mathrm{C}$, durante $48 \mathrm{~h}$. Realizou-se leitura da condutividade elétrica após $1,2,4,8,12,16,24,36,48$ h de embebição, com auxílio de um condutivímetro (Marte, modelo MB11P). Os resultados foram expressos em $\mu \mathrm{S} \mathrm{cm}^{-1} \mathrm{~g}^{-1}$.

Lixiviação de potássio (LK) - O teste foi instalado com quatro amostras de $2 \mathrm{~g}$ de sementes, pesadas e colocadas em copos plásticos, contendo $50 \mathrm{~mL}$ de água destilada, mantidos a $20^{\circ} \mathrm{C}$ por 2,4 , 12 e $24 \mathrm{~h}$. As leituras foram realizadas em fotômetro de chama e os valores foram expressos ppm.mL${ }^{1}$.g- ${ }^{1}$.

Foi adotado o delineamento experimental inteiramente casualizado. Para os dados em porcentagens, utilizou-se a transformação em arco-seno (x /100) $)^{0,5}$, com o objetivo de normalizar a distribuição. Os resultados foram submetidos à análise de variância e as médias comparadas pelo teste de Duncan $(\mathrm{P}<0,05)$. A relação entre os diferentes testes de vigor foi verificada através da correlação simples de Pearson. 


\section{Resultados e Discussão}

Os teores de água inicial dos oito lotes de sementes de aveia branca foram padronizados para valores muito próximos de 13\% (Tabela 1). Esta característica dos lotes é imprescindível para a padronização das avaliações e obtenção de resultados consistentes (LOEFFLER; TEKRONY; EGLI, 1988), pois se evita que os testes sejam afetados por diferenças na atividade metabólica, velocidade de umedecimento e na intensidade de deterioração das sementes por diferenças iniciais de umidade.

Tabela 1. Germinação (G), primeira contagem da germinação (PCG), emergência em areia (AREIA), envelhecimento acelerado (EA), comprimento de plântula (CP), índice de velocidade de emergência (IVE), condutividade elétrica lida com $24 \mathrm{~h}$ (CE), lixiviação de potássio lida com $24 \mathrm{~h}$ (LK), teor de água inicial (TAI) e teor de água após envelhecimento (TAE) na avaliação da qualidade de 8 lotes de sementes de aveia branca, cultivar URS Guria, produzidos em Lages-SC, safra 2010. Os valores apresentados nos testes de CE e LK referem-se a sementes com tempo de embebição de 24 h.

\begin{tabular}{|c|c|c|c|c|c|c|c|c|c|c|}
\hline \multirow{2}{*}{ Lotes } & $\mathrm{G}$ & PCG & AREIA & EA & \multirow{2}{*}{$\frac{\mathrm{CP}}{(\mathrm{cm})}$} & \multirow{2}{*}{ IVE } & \multirow{2}{*}{$\frac{\mathrm{CE}}{\left(\mu \mathrm{S} \cdot \mathrm{cm}^{-1} \cdot \mathrm{g}^{-1}\right)}$} & \multirow{2}{*}{$\frac{\mathrm{LK}}{\left(\mathrm{ppm} \cdot \mathrm{mL}^{-1} \cdot \mathrm{g}^{-1}\right)}$} & \multirow{2}{*}{$\begin{array}{l}\text { TAI } \\
(\%)\end{array}$} & \multirow{2}{*}{$\frac{\text { TAE }}{(\%)}$} \\
\hline & \multicolumn{4}{|c|}{ 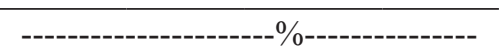 } & & & & & & \\
\hline $1 \mathrm{CF}$ & $92 \mathrm{ab}$ & $90 \mathrm{ab}$ & $83 \mathrm{a}$ & $42 \mathrm{a}$ & $10,3 \mathrm{bc}$ & $12,7 \mathrm{a}$ & $63,0 \mathrm{~b}$ & $4,6 \mathrm{a}$ & 13 & 17,6 \\
\hline $1 \mathrm{SF}$ & $93 \mathrm{ab}$ & $86 \mathrm{ab}$ & $72 \mathrm{a}$ & $37 \mathrm{ab}$ & $9,9 \mathrm{c}$ & $10,5 \mathrm{bc}$ & $108,8 \mathrm{a}$ & $4,5 \mathrm{a}$ & 13 & 14,2 \\
\hline $2 \mathrm{CF}$ & $94 \mathrm{ab}$ & $91 \mathrm{a}$ & 77 a & $28 \mathrm{c}$ & 11,9 a & $12,3 \mathrm{ab}$ & $69,2 \mathrm{~b}$ & $4,0 \mathrm{a}$ & 13 & 18,5 \\
\hline $2 \mathrm{SF}$ & $88 \mathrm{bc}$ & $86 \mathrm{ab}$ & $75 \mathrm{a}$ & $35 \mathrm{~b}$ & $10,2 \mathrm{bc}$ & $11,6 \mathrm{ac}$ & $109,4 \mathrm{a}$ & $4,0 \mathrm{a}$ & 13 & 18,3 \\
\hline $3 \mathrm{CF}$ & $84 \mathrm{c}$ & $82 \mathrm{ab}$ & 77 a & $39 \mathrm{ab}$ & $11,3 \mathrm{ab}$ & $11,2 \mathrm{ac}$ & $70,6 \mathrm{~b}$ & $4,6 \mathrm{a}$ & 13 & 17,3 \\
\hline $3 \mathrm{SF}$ & $84 \mathrm{c}$ & $82 \mathrm{ab}$ & $75 \mathrm{a}$ & $37 \mathrm{ab}$ & $10,4 \mathrm{bc}$ & $11,2 \mathrm{ac}$ & $116,2 \mathrm{a}$ & $3,8 \mathrm{a}$ & 13 & 16,7 \\
\hline $4 \mathrm{CF}$ & $97 \mathrm{a}$ & $89 \mathrm{ab}$ & 77 a & $42 \mathrm{a}$ & $9,1 \mathrm{~cd}$ & $11,1 \mathrm{ac}$ & $67,8 \mathrm{~b}$ & $3,9 \mathrm{a}$ & 13 & 17,7 \\
\hline $4 \mathrm{SF}$ & $91 \mathrm{abc}$ & $80 \mathrm{~b}$ & $74 \mathrm{a}$ & $35 \mathrm{~b}$ & $8,6 \mathrm{~d}$ & $10,2 \mathrm{c}$ & $116,0 \mathrm{a}$ & $4,0 \mathrm{a}$ & 13 & 14,6 \\
\hline Média & 90 & 85 & 76 & 36 & 10,2 & 11,4 & 90,2 & 4,1 & 13 & 17,6 \\
\hline $\mathrm{CV}(\%)$ & 4,9 & 7,3 & 8,8 & 9,1 & 7,6 & 10,0 & 7,4 & 12,8 & 2,1 & 6,9 \\
\hline \multicolumn{11}{|l|}{ Fungicida } \\
\hline Com & $92 \mathrm{~A}$ & $88 \mathrm{~A}$ & 78 & $38 \mathrm{~A}$ & $10,6 \mathrm{~A}$ & $11,8 \mathrm{~A}$ & $67,6 \mathrm{~B}$ & 4,3 & 13 & 17,7 \\
\hline Sem & $89 \mathrm{~B}$ & $83 \mathrm{~B}$ & 74 & $36 \mathrm{~B}$ & $9,7 \mathrm{~B}$ & $10,8 \mathrm{~B}$ & $112,6 \mathrm{~A}$ & 4,1 & 13 & 15,9 \\
\hline
\end{tabular}

Médias seguidas pela mesma letra, na coluna, não diferem entre si pelo teste de Duncan $(\mathrm{P}<0,05)$.

Fonte: Elaboração dos autores.

A percentagem inicial de germinação (G) observada em todos os lotes foram valores superiores a $80 \%$ (Tabela 1); estes valores expressam uma característica importante dos lotes, pois este é o valor mínimo para a comercialização de sementes de aveia branca no Brasil (BRASIL, 2005). Porém, resultados elevados de germinação não indicam, necessariamente, que os lotes possuem alto vigor, uma vez que o teste é conduzido em condições favoráveis, permitindo ao lote expressar potencial máximo em gerar plântulas normais (MARCOS FILHO et al., 1999). Portanto, é necessária a realização de testes que avaliem diferenças quanto ao vigor de lotes de sementes. Mas a germinação diferiu entre os lotes sendo menor nos lotes $3 \mathrm{CF}$ e $3 \mathrm{SF}$ ( 84\%) e maior valor observado no lote $4 \mathrm{CF}$ (97\%) (Tabela 1).

Dentre os testes de vigor realizados, os testes de primeira contagem da germinação, envelhecimento acelerado, comprimento de plântula, índice de velocidade de emergência e condutividade elétrica foram os mais sensíveis, sendo capazes de separar lotes em diferentes classes de vigor (Tabela 1). Verificou-se que o teste de primeira contagem separou os lotes em duas classes de vigor (lote $2 \mathrm{CF}$ 
foi o de maior vigor e o $4 \mathrm{SF}$ de menor). $\mathrm{O}$ teste de envelhecimento acelerado separou os lotes em três classes $(1 \mathrm{CF}$ e $4 \mathrm{CF}$ os de maior valor e $2 \mathrm{CF}$ de menor germinação). O teste de comprimento de plântula diferenciou os lotes em quatro níveis de vigor (novamente o lote $2 \mathrm{CF}$ apresentou maior vigor e o $4 \mathrm{SF}$ o menor). $\mathrm{O}$ índice de velocidade de emergência dividiu os lotes em três classes (lote $1 \mathrm{CF}$ obteve maior valor e o $4 \mathrm{SF}$ menor). O teste de condutividade elétrica avaliado após embebição por $24 \mathrm{~h}$ separou os lotes em duas classes de vigor (Tabela 1).

De modo geral, observou-se na separação dos lotes em diferentes níveis de qualidade fisiológica, tendência dos testes em destacar os lotes $1 \mathrm{CF}$ e $3 \mathrm{CF}$ como superiores e $4 \mathrm{SF}$ como o lote inferior; uma separação mais eficiente não foi possível, provavelmente, pelos lotes apresentarem qualidade fisiológica semelhante, caso seja considerado apenas os resultados dos testes AREIA, LK, TAI e TAE (Tabela 1).

No teste de lixiviação de potássio (LK), avaliando-se o comportamento das sementes em diferentes períodos de embebição, observou-se que o tempo de $24 \mathrm{~h}$ de condução do teste é ineficiente para separar os lotes, mas com tempos menores foi possível, particularmente tempos de 4 e $12 \mathrm{~h}$ que foram mais consistentes na separação dos lotes, permitindo inferir que os lotes oriundos de plantas tratadas com fungicida apresentaram maior vigor de sementes comparados aos lotes formados por sementes oriundas de plantas não tratados com fungicida (Tabela 2). A estratificação dos lotes em diferentes níveis de vigor foi possível apenas com duas, quatro e $12 \mathrm{~h}$ de embebição, dentro dos períodos estudados.

Quanto ao teste de condutividade elétrica, observou-se que os lotes formados pelas sementes em que as plantas foram pulverizadas com fungicida apresentaram os menores valores de $\mathrm{CE}$, demonstrando efeito da aplicação de fungicida (Figura1). Este comportamento provavelmente ocorreu porque, de um modo geral, as sementes CF apresentaram maior vigor, portanto possuem maior integridade das membranas celulares das sementes e apresentam maior velocidade de estruturação destas membranas quando embebidas em água, tendo como consequência menor liberação de exsudatos para o exterior da célula que aquelas menos vigorosas (SF). Tendência esta também observada no teste de LK conduzido por 2, 4 e 12 horas.

Observou-se, também, aumento no valor de condutividade (CE) com o aumento do período de embebição, corroborando com resultados de pesquisas sobre o assunto (VIEIRA et al., 1996; DIAS; MARCOS FILHO, 1996) (Figura 1). Este comportamento foi observado em todos os lotes testados (Tabela 3).

Verificou-se que, com uma e duas horas de embebição, já foi possível a classificação dos lotes quanto ao potencial fisiológico, sendo o período de uma hora, o único que separou os lotes em quatro níveis de vigor, os outros períodos em apenas dois níveis (Tabela 3). Além disso, observou-se que, quando realizada a mensuração da condutividade elétrica após as sementes serem hidratadas por uma e duas horas, encontraram-se os resultados que mais se aproximaram dos outros testes de vigor em relação ao ranqueamento dos lotes pela qualidade fisiológica. Este fato é de extrema importância pois possibilita uma redução significativa no período de execução do teste, diminuindo o tempo de condicionamento das sementes para uma hora, e não mais $24 \mathrm{~h}$, adotado pela pesquisa como padrão para testes de condutividade elétrica para ervilha e soja (HAMPTON; TEKRONY, 1995; VIEIRA; KRZYZANOWSKI, 1999). 
Tabela 2. Lixiviação de potássio $\left(\mathrm{ppm} \cdot \mathrm{mL}^{-1} \cdot \mathrm{g}^{-1}\right)$ na avaliação da qualidade de 8 lotes de sementes aveia branca, cultivar URS Guria, produzidos em Lages-SC, safra 2010.

\begin{tabular}{|c|c|c|c|c|}
\hline Lotes & 2 & 4 & 12 & 24 \\
\hline & \multicolumn{4}{|c|}{ 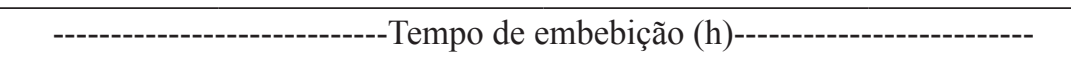 } \\
\hline & \multicolumn{4}{|c|}{ 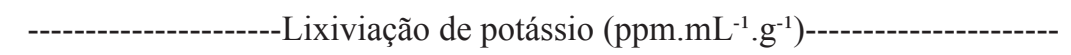 } \\
\hline $1 \mathrm{CF}$ & $2,0 \mathrm{~d}$ & $2,9 \mathrm{~b}$ & $3,8 \mathrm{c}$ & $4,6 \mathrm{a}$ \\
\hline $1 \mathrm{SF}$ & $3,7 \mathrm{~b}$ & $5,5 \mathrm{a}$ & $3,7 \mathrm{c}$ & $4,5 \mathrm{a}$ \\
\hline $2 \mathrm{CF}$ & $2,6 \mathrm{c}$ & $3,2 \mathrm{~b}$ & $4,1 \mathrm{c}$ & $4,0 \mathrm{a}$ \\
\hline $2 \mathrm{SF}$ & $4,3 \mathrm{a}$ & $5,1 \mathrm{a}$ & $4,8 \mathrm{~b}$ & $4,0 \mathrm{a}$ \\
\hline $3 \mathrm{CF}$ & $2,6 \mathrm{c}$ & $3,4 \mathrm{~b}$ & $4,0 \mathrm{c}$ & $4,6 \mathrm{a}$ \\
\hline $3 \mathrm{SF}$ & $3,9 \mathrm{ab}$ & $5,3 \mathrm{a}$ & $6,1 \mathrm{a}$ & $3,8 \mathrm{a}$ \\
\hline $4 \mathrm{CF}$ & $2,5 \mathrm{~cd}$ & $3,0 \mathrm{~b}$ & $3,8 \mathrm{c}$ & $3,9 \mathrm{a}$ \\
\hline $4 \mathrm{SF}$ & $4,3 \mathrm{a}$ & $5,5 \mathrm{a}$ & $4,0 \mathrm{c}$ & $4,0 \mathrm{a}$ \\
\hline Média & 3,3 & 4,4 & 4,3 & 4,1 \\
\hline $\mathrm{CV}(\%)$ & 10,8 & 11,3 & 8,7 & 12,8 \\
\hline \multicolumn{5}{|l|}{ Fungicida } \\
\hline Com & $2,4 \mathrm{~B}$ & $3,2 \mathrm{~B}$ & $4,0 \mathrm{~B}$ & $4,3 \mathrm{~A}$ \\
\hline Sem & $4,1 \mathrm{~A}$ & $5,4 \mathrm{~A}$ & $4,8 \mathrm{~A}$ & $4,1 \mathrm{~A}$ \\
\hline
\end{tabular}

Médias seguidas pela mesma letra, na coluna, não diferem entre si pelo teste de Duncan $(\mathrm{P}<0,05)$.

Fonte: Elaboração dos autores.

Figura 1. Condutividade elétrica $\left(\mu \mathrm{S} . \mathrm{cm}^{-1} \cdot \mathrm{g}^{-1}\right)$ de sementes aveia branca, cultivar URS Guria, no teste conduzido por até $48 \mathrm{~h}$ de embebição, em lotes de sementes produzidos com (CF) e sem (SF) aplicação de fungicida, em Lages-SC, na safra 2010. Barras significam o erro padrão da média.

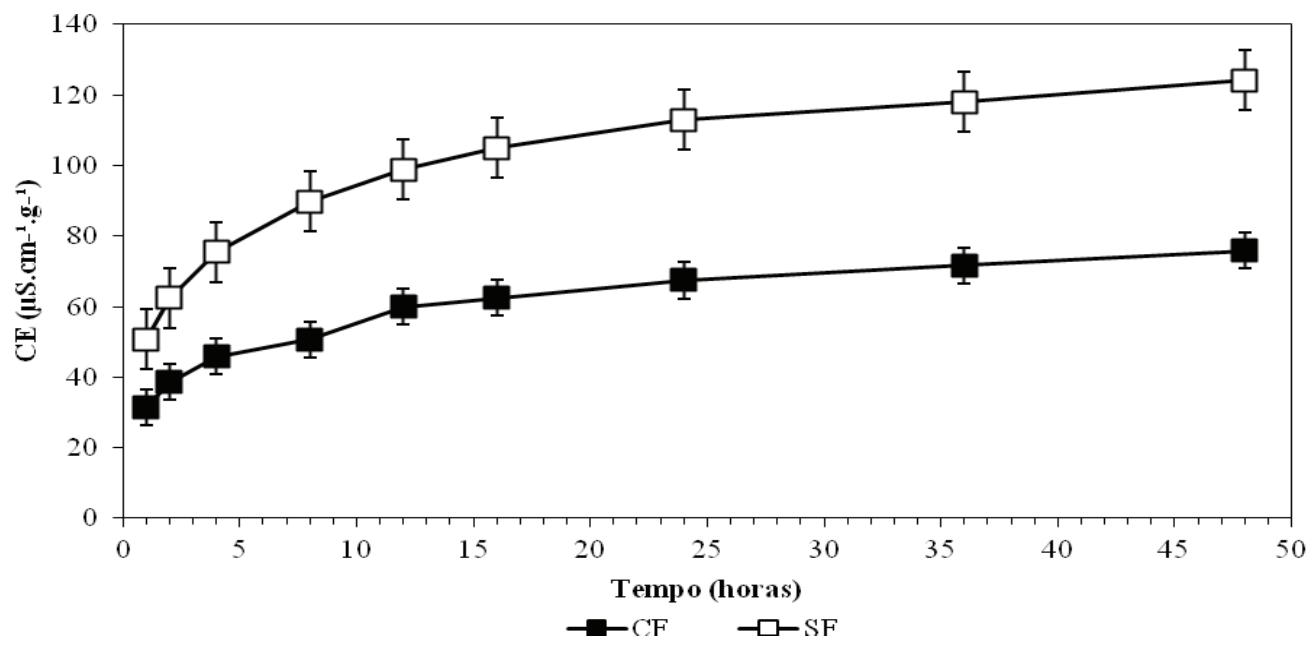

Fonte: Elaboração dos autores. 
Tabela 3. Condutividade elétrica $\left(\mu \mathrm{S} . \mathrm{cm}^{-1} \cdot \mathrm{g}^{-1}\right)$ na avaliação da qualidade de 8 lotes de sementes aveia branca, cultivar URS Guria, produzidos em Lages-SC, safra 2010.

\begin{tabular}{|c|c|c|c|c|c|c|c|c|c|}
\hline Lotes & 1 & 2 & 4 & 8 & 12 & 16 & 24 & 36 & 48 \\
\hline \multicolumn{10}{|c|}{ 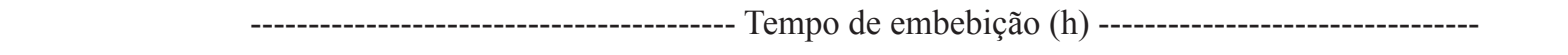 } \\
\hline & & & & Condut & dade Elét & a (uS.cm & $-1)$ & & ----- \\
\hline $1 \mathrm{CF}$ & $27,6 \mathrm{~d}$ & $35,4 \mathrm{~b}$ & $41,9 \mathrm{~b}$ & $50,4 \mathrm{~b}$ & $56,1 \mathrm{~b}$ & $59,3 \mathrm{~b}$ & $63,0 \mathrm{~b}$ & $67,7 \mathrm{~b}$ & $73,9 \mathrm{~b}$ \\
\hline $1 \mathrm{SF}$ & $47,2 \mathrm{~b}$ & $60,8 \mathrm{a}$ & $73,6 \mathrm{a}$ & 87,3 a & 96,4 a & $102,2 \mathrm{a}$ & $108,8 \mathrm{a}$ & $113,0 \mathrm{a}$ & $119,4 \mathrm{a}$ \\
\hline $2 \mathrm{CF}$ & $32,6 \mathrm{c}$ & $39,1 \mathrm{~b}$ & $46,8 \mathrm{~b}$ & $43,5 \mathrm{~b}$ & $61,3 \mathrm{~b}$ & $64,1 \mathrm{~b}$ & $69,2 \mathrm{~b}$ & $73,5 \mathrm{~b}$ & $77,1 \mathrm{~b}$ \\
\hline $2 \mathrm{SF}$ & $47,8 \mathrm{~b}$ & $59,1 \mathrm{a}$ & $71,7 \mathrm{a}$ & $86,5 \mathrm{a}$ & $93,4 \mathrm{a}$ & $100,9 \mathrm{a}$ & $109,4 \mathrm{a}$ & $112,6 \mathrm{a}$ & $121,6 \mathrm{a}$ \\
\hline $3 \mathrm{CF}$ & $34,2 \mathrm{c}$ & $41,3 \mathrm{~b}$ & $48,9 \mathrm{~b}$ & $55,3 \mathrm{~b}$ & $63,1 \mathrm{~b}$ & $65,8 \mathrm{~b}$ & $70,6 \mathrm{~b}$ & $74,8 \mathrm{~b}$ & $78,0 \mathrm{~b}$ \\
\hline $3 \mathrm{SF}$ & $52,6 \mathrm{a}$ & $64,4 \mathrm{a}$ & $77,7 \mathrm{a}$ & $92,6 \mathrm{a}$ & $102,5 \mathrm{a}$ & $108,0 \mathrm{a}$ & $116,2 \mathrm{a}$ & $124,2 \mathrm{a}$ & $129,5 \mathrm{a}$ \\
\hline $4 \mathrm{CF}$ & $32,1 \mathrm{~cd}$ & $39,1 \mathrm{~b}$ & $46,3 \mathrm{~b}$ & $54,8 \mathrm{~b}$ & $60,0 \mathrm{~b}$ & $61,8 \mathrm{~b}$ & $67,8 \mathrm{~b}$ & $71,4 \mathrm{~b}$ & $74,9 \mathrm{~b}$ \\
\hline $4 \mathrm{SF}$ & $54,2 \mathrm{a}$ & $65,0 \mathrm{a}$ & $78,2 \mathrm{a}$ & $92,2 \mathrm{a}$ & $102,7 \mathrm{a}$ & $108,4 \mathrm{a}$ & $116,0 \mathrm{a}$ & $67,7 \mathrm{~b}$ & $125,2 \mathrm{a}$ \\
\hline Média & 41,0 & 50,5 & 60,6 & 70,3 & 79,5 & 83,8 & 90,2 & 94,9 & 100,1 \\
\hline CV (\%) & 7,2 & 7,6 & 7,4 & 14,4 & 8,1 & 7,5 & 7,4 & 4,5 & 7,4 \\
\hline
\end{tabular}

Médias seguidas pela mesma letra, na coluna, não diferem entre si pelo teste de Duncan $(\mathrm{P}<0,05)$.

Fonte: Elaboração dos autores.

Um fato que dever ser destacado é a superioridade na qualidade fisiológica demonstrada pelos lotes provenientes de plantas tratadas com fungicida em todos os testes realizados. Portanto, a aplicação de fungicida mostrou ser uma prática importante para a cultura de aveia branca, visando à produção de sementes com elevado potencial fisiológico. Esta técnica também foi eficiente para a cultura do arroz que em decorrência de aplicações de fungicida na parte aérea das plantas observaram-se a melhoria na germinação e o vigor das sementes produzidas e, além disso, reduziu a incidência de fungos associados às sementes (TELÓ et al., 2012).

Para uma análise do grau de associação entre todos os testes, foi realizada a análise de correlação simples (Tabela 4). Observou-se, que o teste de primeira contagem da germinação, obteve correlação positiva com germinação, emergência em areia, índice de velocidade de emergência e negativa com condutividade elétrica (Tabela 4). Dos testes realizados, apenas o teste de envelhecimento acelerado não se correlacionou com nenhum outro.

O teste de emergência em areia não obteve correlação significativa com a germinação (Tabela
4). Estes resultados demonstram diferenças no comportamento das sementes quando submetidas a distintas condições, uma vez que o teste de germinação é realizado em condições ótimas de luminosidade, temperatura e umidade, o que não ocorre em condições mais próximas às de campo, na emergência em areia. Este comportamento semelhante também foi encontrado em sementes de cenoura (LIMA; ATHANÁZIO, 2009).

Para os dados obtidos na condutividade elétrica, houve correlação negativa significativa com primeira contagem, emergência em areia e índice de velocidade de emergência, demonstrando que aumento nos valores de condutividade elétrica correspondeu a reduções no vigor das sementes nestes testes (Tabela 4). Estes resultados concordam com as observações de Carvalho et al. (2009) que constataram correlações significativas entre os valores de condutividade elétrica com primeira contagem e emergência em areia, em sementes de soja. O teste de condutividade elétrica se correlacionou significativamente $(\mathrm{P}<0,05)$ e negativamente com os testes de vigor: primeira contagem da germinação, emergência em areia 
e índice de velocidade de emergência e também correlação negativa, porém fraca $(\mathrm{P}<0,10)$ com os testes de: germinação, envelhecimento acelerado, comprimento de plântula e lixiviação de potássio.

Tabela 4. Correlação simples de Pearson entre os parâmetros germinação $(G)$, primeira contagem da germinação (PCG), emergência em areia (AREIA), envelhecimento acelerado (EA), comprimento de plântula (CP), índice de velocidade de emergência (IVE), condutividade elétrica (CE) e lixiviação de potássio (LK) na avaliação da qualidade de 8 lotes de sementes de aveia branca, cultivar URS Guria, produzidos em Lages-SC, safra 2010.

\begin{tabular}{|c|c|c|c|c|c|c|c|c|c|c|c|c|}
\hline & $\mathrm{G}$ & & PCG & & AREIA & & EA & $\mathrm{CP}$ & & IVE & $\mathrm{CE}$ & LK \\
\hline G & 1,00 & & & & & & & & & & & \\
\hline PCG & 0,68 & $*$ & 1,00 & & & & & & & & & \\
\hline AREIA & 0,12 & & 0,52 & $*$ & 1,00 & & & & & & & \\
\hline EA & 0,00 & & $-0,05$ & & 0,38 & & 1,00 & & & & & \\
\hline $\mathrm{CP}$ & $-0,31$ & & 0,33 & & 0,27 & & $-0,44$ & 1,00 & & & & \\
\hline IVE & $-0,14$ & & 0,54 & $*$ & 0,81 & $*$ & 0,02 & 0,75 & $*$ & 1,00 & & \\
\hline $\mathrm{CE}$ & $-0,37$ & & $-0,66$ & $*$ & $-0,76$ & $*$ & $-0,25$ & $-0,42$ & & $-0,74$ & 1,00 & \\
\hline LK & $-0,08$ & & 0,09 & & 0,34 & & 0,37 & 0,25 & & 0,37 & $-0,38$ & 1,00 \\
\hline
\end{tabular}

* significativo a pelo menos $5 \%$ pelo teste $\mathrm{T}$.

Fonte: Elaboração dos autores.

\section{Conclusão}

O teste de condutividade elétrica é eficiente para estratificar lotes de sementes de maneira consistente. O período de embebição de duas a quatro horas possibilita a identificação de lotes com diferentes níveis de vigor de sementes de aveia branca.

\section{Agradecimentos}

A CAPES pela concessão de bolsa de mestrado ao primeiro autor e ao CNPq pela concessão de bolsa de produtividade em pesquisa ao terceiro autor.

\section{Referências}

ALVES, C. Z.; GODOY, A. R.; CANDIDO, A. C. S.; OLIVEIRA, N. C.Teste de condutividade elétrica na avaliação do potencial fisiológico de sementes de berinjela. Ciência Rural, Santa Maria, v. 42, n. 6, p. $975-$ 980, 2012.

ANDRADE, R. N. B.; SANTOS, D. S. B.; SANTOS FILHO, B. G.; MELLO, V. D. C. Correlação entre testes de vigor em sementes de cenoura armazenadas por diferentes períodos. Pesquisa Agropecuária Gaúcha, Porto Alegre, v. 1, n. 2, p. 153-162, 1995.

ARAÚJO, R. F.; ZONTA, J. B.; ARAUJO, E. F.; DONZELES, S. M. L.; COSTA, G. M. Teste de condutividade elétrica para sementes de pinhão-manso (Jatropha curcas L.). Idesia, Arica, v. 29, n. 2, p. 79-86, 2011.

BORSATO, A. V.; BARROS, A. S. do R.; AHYENS, D. C.; DIAS, M. C. L. de L. Avaliação de testes de vigor para sementes de aveia-branca (Avena sativa L.). Revista Brasileira de Sementes, Brasília, v. 22, n. 1, p. 163-168, 2000.

BRASIL. Ministério da Agricultura, Pecuária e Abastecimento. Padrões para produção e comercialização de sementes de mamona cultivares não híbridas (variedades). Instrução normativa $\mathrm{n}^{\circ} 25$, de 16 de dezembro de 2005. Diário Oficial [da] União, Brasília, 20 dez. 2005. Seção 1, n. 243, p. 18.

- Ministério da Agricultura, Pecuária e Abastecimento. Secretaria de Defesa Agropecuária. Regras para análise de sementes. Brasília, DF: MAPA/ ACS, 2009. 395 p.

BRUGGINK, H.; KRAAK, H. L.; DIJEMA, M. H. G. E.; BEKENDAM, J. Some factors influencing electrolyte leakage from maize (Zea mays L.) kernels. Seed Science and Research, Wageningen, v. 1, n. 1, p. 15-20, 1991. 
CARVALHO, L. F.; SEDIYAMA, C. S.; DIAS, D. C. F. S.; REIS, M. S.; MOREIRA, M. A. Teste rápido de condutividade elétrica e correlação com outros testes de vigor. Revista Brasileira de Sementes, Londrina, v. 31, n. 1, p. 239-248, 2009.

COELHO, C. M. M.; MOTA, M. R.; SOUZA, C. A.; MIQUELLUTI, D. J. Potencial fisiológico em sementes de cultivares de feijão crioulo (Phaseolus vulgaris L.). Revista Brasileira de Sementes, Londrina, v. 32, n. 3, p. 97-105, 2010.

DIAS, D. C. F. S.; MARCOS FILHO, J. Testes de condutividade elétrica para avaliação do vigor de sementes de soja. Scientia Agricola, Piracicaba, v. 53, n. 1, p. 31-42, 1996.

FONTANELI, R. S. Valor nutritivo das aveias para produção animal. In: REUNIÃO ANUAL DA COMISSÃO BRASILEIRA DE PESQUISA DE AVEIA, 22., 2012, Passo Fundo. Palestra... Passo Fundo: EMBRAPA, 2012. p. 1-12.

GASPAR, C. M.; NAKAGAWA, J. Teste de condutividade elétrica em função do período e da temperatura de embebição para sementes de milheto. Revista Brasileira de Sementes, Brasília, v. 24, n. 2, p. 82-89, 2002.

HAMPTON, J. G.; TEKRONY, D. M. Manual de métodos de teste de vigor. Zurich: ISTA, 1995. $117 \mathrm{p}$.

LEAL, C. C. P.; TORRES, S. B.; NOGUEIRA, N. W.; TOMCZAK, V. E.; BENEDITO, C. P. Validação de testes de vigor para sementes de rúcula (Eruca sativa L.). Revista Brasileira de Biociências, Porto Alegre, v. 10, n. 3, p. 421-424, 2012.

LIMA, C. B.; ATHANÁZIO, J. C. Testes de vigor para sementes de cenoura. Scientia Agraria, Curitiba, v. 10, n. 6, p. 455-461, 2009.

LOEFFLER, L. M.; TEKRONY, D. M.; EGLI, D. B. The bulk conductivity test as an indicator of soybean seed quality. Journal of Seed Technology, Lincoln, v. 12, n. 1, p. 37-53, 1988.

MAGUIRE, J. B. Speed of germination-aid in selection and evaluation for seedling emergence vigor. Crop Science, Madison, v. 2, n. 2, p. 176-177, 1962.

MARCOS FILHO, J. Fisiologia de sementes de plantas cultivadas. Piracicaba: FEALQ, 2005. 495 p.
MARCOS FILHO, J.; KRZYZANOWSKI, F. C.; VIEIRA, R. D.; FRANÇA NETO, J. B. Vigor de sementes: conceitos e testes. Londrina: ABRATES, 1999. cap. 3, p. 1-24.

MENEZES, N. L.; GARCIA, D. C.; BAHRY, C. A.; MATTIONI, N. M. Teste de condutividade elétrica em aveia preta. Revista Brasileira de Sementes, Pelotas, v. 29, n. 2, p. 138-142, 2007.

PRETE, C. E. C.; ABRAHÃO, J. T. M. Condutividade elétrica dos exsudados de grãos de café (Coffea arabica L) I: desenvolvimento da metodologia. Semina: Ciências Agrárias, Londrina, v. 16, n. 1, p. 17-21, 1995.

RADIN, B.; REISSER JÚNIOR, C. R.; PANDOLFO, C. Atlas climático da região sul do Brasil. Brasília: EMBRAPA, 2011. 336 p.

SILVA, L. B. da; MARTINS, C. C. Teste de condutividade elétrica para sementes de mamoneira. Semina: Ciências Agrárias, Londrina, v. 30, p. 1043-1050, 2009. Suplemento 1.

TEKRONY, D. M. Precision is an essential component in seed vigour testing. Seed Science and Technology, Zürich, v. 31, n. 2, p. 435-447, 2003.

TELÓ, G.; MARCHESAN, E.; MENEZES, N. L.; FERREIRA, R. B.; SARTORI, G. M. S.; FORMENTINI, T. C.; HANSEL, D. S. S. Aplicação de fungicida em cultivares de arroz irrigado e seu efeito na qualidade de sementes. Revista Brasileira de Sementes, Londrina, v. 34, n. 1, p. 99-107, 2012.

TUNES, L. M de; OLIVO, F.; BADINELLI, P. G.; CANTOS, A.; BARROS, A. C. S. A. Testes de vigor em sementes de aveia branca. Revista da FZVA, Uruguaiana, v. 15, n. 2, p. 94-106. 2008.

VIEIRA, R. D.; KRZYZANOWSKI, F. C. Teste de condutividade elétrica. In: KRZYZANOWSKI, F. C.; VIEIRA, R. D.; FRANÇA NETO, J. B. (Ed.). Vigor de sementes: conceitos e testes. Londrina: ABRATES, 1999. cap. 4, p. 1-26.

VIEIRA, R. D.; PANOBIANCO, M.; LEMOS, L. B.; FORNASIERI FILHO, D. Efeito de genótipos de feijão e de soja sobre os resultados da condutividade elétrica de sementes. Revista Brasileira de Sementes, Brasília, v. 18, n. 2, p. 220-224, 1996. 